\title{
What's in a name?
}

In this Editor's choice (BMJ 2013;347:f7543, doi:10.1136/bmj. f7543), Bruce Arroll and Felicity Goodyear-Smith, two of the coauthors of a Christmas paper, were incorrectly identified as "husband and wife." 